\title{
Development of a Jerte Valley cherry-based beverage by fermentation of lactic acid bacteria and characterization of its potential functional value
}

\author{
Maria Garrido', Maria Elena Bote², Daniel Moreno ${ }^{3}$, Jonathan Delgado-Adamez ${ }^{3^{*}}$ \\ ${ }^{1}$ Department of Physiology (Neuroimmunophysiology and Chrononutrition Research Group), Faculty of Science, University of Extremadura. \\ Avda. Elvas s/n 06006 Badajoz (Spain), ${ }^{2}$ Department of Physiology (Immunophysiology Research Group), Faculty of Science, University \\ of Extremadura. Avda. Elvas s/n 06006 Badajoz (Spain), ${ }^{3}$ Technological Institute of Food and Agriculture (CICYTEX-INTAEX). Junta de \\ Extremadura. Av. Adolfo Suárez s/n 06071 Badajoz (Spain)
}

\section{A B S T R A C T}

\begin{abstract}
Lactic fermentation is a low-cost and sustainable bio-preservation method that aims to retain the sensory and nutritional characteristics of raw matrices. In this study two lactic fermentation processes were set up to elaborate two fermented cherry beverages as well as to determine their nutritional and functional characteristics. Differences between both processes were based on the pasteurization conditions and ascorbic acid addition time. The results were compared with those obtained in cherry fresh fruit and two pasteurized cherry purées. The purée and beverage obtained through protocol 2 (where ascorbic acid addition was carried out before the pasteurization process, which was applied during 5 minutes) were the most effective in preserving the reddish color of fruits compared to those obtained in protocol 1 (where ascorbic acid addition was carried out after the pasteurization process, which was applied during 10 minutes). Similarly, protocol 2 was more efficient in preventing the loss of phenolic compounds and anthocyanins. The levels of serotonin did not change after the fermentation processes, whereas the amino acid concentration was higher in cherry-fermented beverages. Better results were obtained in cherry-fermented beverages. The lactic fermentation could be a useful and feasible technique to obtain natural drinks with functional / nutritional qualities.
\end{abstract}

Keywords: Lactic acid fermentation; Lactobacillus plantarum; Pediococcus pentosaceus; sweet cherry.

\section{INTRODUCTION}

The cherry fruit is rich in of phytochemicals, including anthocyanins, quercetin, and carotenoids, that are reported to present antioxidant, anticancer, antidiabetic, anti-obesity, and anti-inflammatory properties (Blando and Oomah, 2019; Faienza et al., 2020). In fact, this fruit inhibits cyclooxygenase enzymes, which are responsible for inflammatory responses, and reduces inflammatory markers as the levels of serum C-reactive protein (CRP) (Delgado et al., 2012; Mulabagal et al., 2009).

It has been proposed that the positive effects exerted by the consumption of vegetables and fruits come from the additive and synergistic effects of their phytonutrients (Hugo et al., 2012; Linnewiel-Hermoni et al., 2015). At this respect, sweet cherries (Prunus avium L.) from the
Jerte Valley (Extremadura, Spain) are composed, not only. by anthocyanin pigments and other phenolic compounds (González-Gómez et al., 2010), but also by high levels of tryptophan (Cubero et al., 2010), serotonin, and melatonin (González-Gómez et al., 2009), molecules with well-known antioxidant properties (Espino et al., 2011; Nayak and Buttar, 2016). These phytochemicals can play a role as dietary therapeutics or nutraceuticals and, therefore, some plant foods and beverages can be considered as functional products by virtue of their content.

Sweet cherries are mainly consumed as fresh fruit. Nevertheless, taking into account that cherry season is relatively short (from May to August), a large part of the harvest is processed as brined, canned and frozen, dried, or used for juices or syrups. Consumers request highquality processed fruit products with fresh-like flavor,

\footnotetext{
${ }^{*}$ Corresponding author:

Jonathan Delgado-Adámez, PhD., Technological Institute of Food and Agriculture (CICYTEX-INTAEX). Junta de Extremadura. Av. Adolfo

Suárez s/n 06071 Badajoz (Spain). Phone: +34 924 012666. Fax: +34 924 012674. E-mail: jonathan.delgado@juntaex.es
}

Received: 20 May 2020; $\quad$ Accepted: 18 September 2020 
microbiologically safe and free from additives. Consequently, they greatly appreciate the fresh appearance of minimally processed food. Traditionally, thermal pasteurization has been used to inactivate microorganisms and enzymes and extend the shelf-life of these products. However, the applied heat can cause undesirable consequences in terms of reducing the sensory and nutritional properties of processed food (Patras et al., 2010). Lactic fermentation is a low-cost and sustainable bio-preservation method that aims to retain the sensory and nutritional characteristics of raw matrices and extend shelf life under safe conditions (Di Cagno et al., 2009; Liao et al., 2016). Vegetable juices can be fermented by three different processes: spontaneous fermentation by natural microflora; fermentation by starter cultures that are added into raw matrices; and fermentation of mild heat-treated vegetables by starter cultures. As far as hygiene and safety are concerned, the use of starter cultures is recommended as it would lead to a rapid inhibition of spoilage and pathogenic bacteria and to preserve the consistent sensory and nutritional quality of processed fruit (Torres et al., 2020). It has been shown that the use of selected autochthonous lactic acid bacteria as starters culture guaranteed the prolonged shelf-life of vegetables and fruits which also maintained agreeable nutritional, rheology and sensory properties (Di Cagno et al., 2009, 2011; Yang et al., 2018). Furthermore, lactic acid bacteria as Lactobacillus and their fermented products are effective at improving innate and adaptive immunity, preserving gastric mucosal, alleviating allergies, and putting up defense against intestinal infection (Tsai et al., 2012). Importantly, the biodiversity of lactic acid bacteria of sweet cherry fruits is composed of Lactobacillus plantarum, which is one of the species most frequently found or used to ferment vegetables and fruits (Di Cagno et al., 2009, 2011), Pediococcus acidilactici, Pediococcus pentosaceus and Leuconostoc mesenteroides subsp. mesenteroides (Di Cagno et al., 2011).

Based on this background, the aim of the present study was to set up two lactic fermentation processes, particularly by starter cultures, to elaborate two fermented cherry beverages as well as to determine their nutritional and functional characteristics. Likewise, the results are compared with those obtained in cherry fresh fruit and two pasteurized cherry purées.

\section{MATERIAL AND METHODS}

\section{Plant material}

Sweet cherry fruit cv. 'Sweatheart' was obtained from Jerte Valley (Extremadura, Spain) local farmers in 2018. The fruit was harvested at the commercial ripening stage and was transported in refrigerated containers to Technological Agri-Food Institute (CICYTEX-Intaex), where cherries were also preserved at $4{ }^{\circ} \mathrm{C}$. Upon arrival, non-damaged cherries were selected according to approximate uniform size and weight. Roughly 40-50 ripe cherries were selected to analyze fruit quality parameters. The fresh fruit analysis and the elaboration and analysis of cherry purées and fermented-cherry beverages were developed within seven days; otherwise, fruit, purées and beverages were stored at $-40{ }^{\circ} \mathrm{C}$ until their analysis.

\section{Bacterial strains and conditions}

Two strains of lactic acid bacteria, namely $P$. pentosaceus and L. plantarum, were acquired from the Spanish Type Culture Collection (CECT), cultured in MRS broth (Merck 110660) and incubated at $30^{\circ} \mathrm{C}$ for $24 \mathrm{~h}$. The cells were harvested by centrifugation at $10,000 \times \mathrm{g}$ for $10 \mathrm{~min}$ at $4^{\circ} \mathrm{C}$ and washed twice with sterile phosphate buffer (0.05 M,pH 7.0). Finally, cells were resuspended in sterile distilled water to evaluate a final optical density of $620 \mathrm{~nm}$ (OD620) of 2.5 (final cell number corresponding to approximately $\left.9.0 \log \mathrm{cfu} \mathrm{mL}^{-1}\right)$.

\section{Fermented cherry-based beverages manufacture}

Two protocols with slight differences were carried out to obtain two fermented cherry-based beverages (Scheme 1 and Scheme 2). Differences between both processes were based on the pasteurization conditions and ascorbic acid addition time.

\section{Color measurements}

Five color determinations were carried out in three batches of the two beverages and the two cherry purees, the result being the mean of each batch. A Konica Minolta Spectrophotometer CM-3500d (Ramsey, N.J., U.S.A.) was used to performance the instrumental color measurements, whereas, transmittance measurements were made using a geometry $\mathrm{d} / 0$ (diffuse illumination and $0^{\circ}$ viewing angle) with the primary illuminant D65. Readings were reported in the CIELAB color system: $\mathrm{L}^{*}$ (lightness), a* (red \pm green), $\mathrm{b}^{*}$ (yellow \pm blue). Moreover, two physical parameters were measured, $\mathrm{C}_{\mathrm{ab}}^{*}$ (chroma) and $\mathrm{h}_{\mathrm{ab}}$ (hue angle), that are associated with $\mathrm{a}^{*}$ and $\mathrm{b}^{*}$ according to the following expressions:

$$
\begin{aligned}
& \mathrm{C}_{\mathrm{ab}}^{*}=\left[\mathrm{a}^{* 2}+\mathrm{b}^{* 2}\right]^{0.5} \\
& \mathrm{~h}_{\mathrm{ab}}=\operatorname{arctg} \mathrm{b}^{*} / \mathrm{a}^{*}
\end{aligned}
$$

\section{Total polyphenols content}

Phenolic compounds were extracted from $5 \mathrm{~g}$ of fresh sample following the method of Lima et al., (2005) with slight modifications. Phenolic content was determined using the Folin-Ciocalteu reagent according to a method previously published (Singleton and Rossi, 1965). The absorbance was measured at $760 \mathrm{~nm}$ in a UV-2401 PC Shimadzu spectrophotometer (Scientific Instruments, Inc., Columbia, MD., USA) using gallic acid as standard. Results were expressed as milligram of gallic acid equivalent/100 $\mathrm{g}$ sample. 


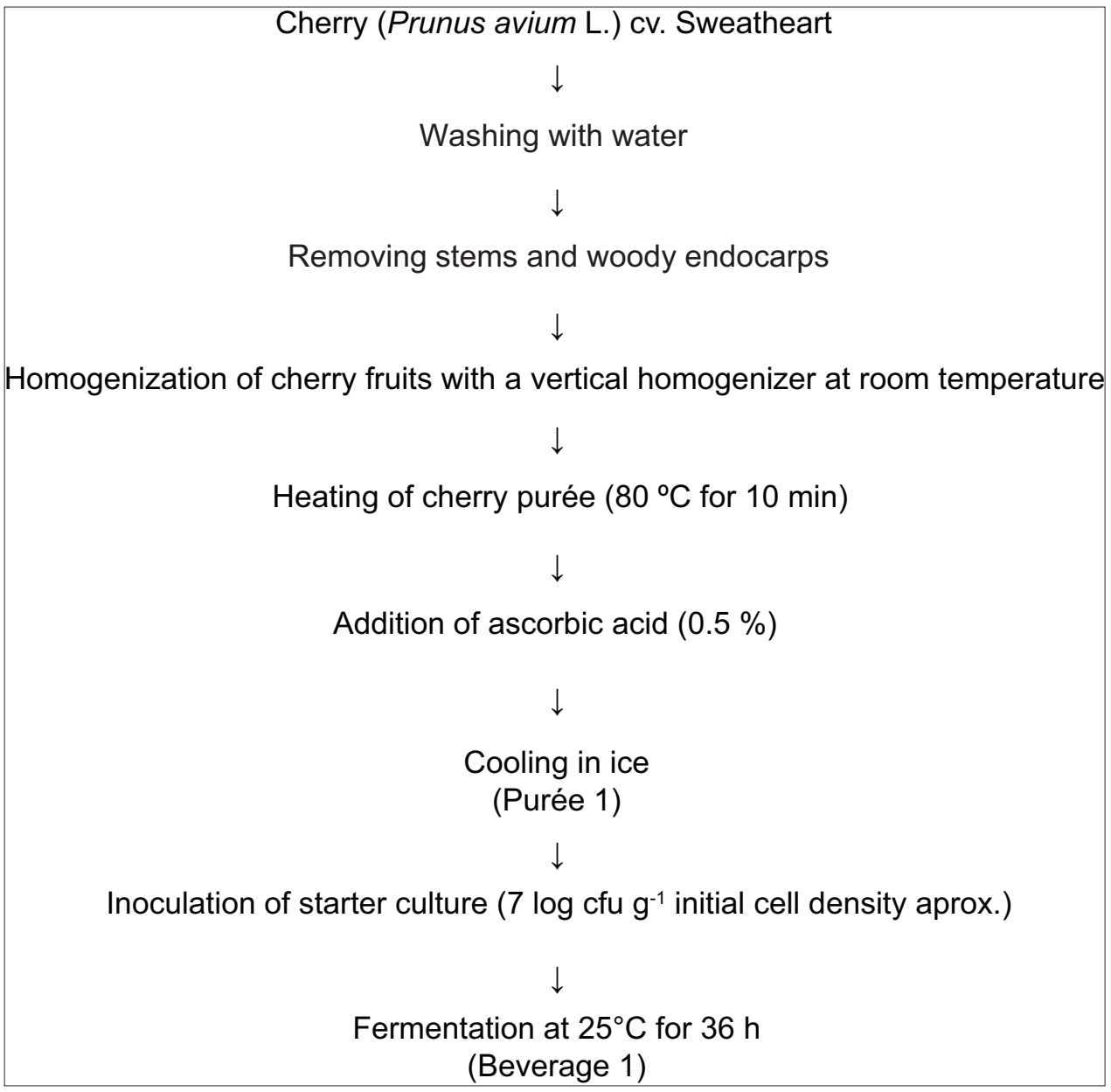

Scheme 1. Protocol for the elaboration of the fermented cherry-based beverage 1.

\section{Quantification of total anthocyanins content}

Anthocyanins were extracted following a method described elsewhere (Bernalte et al., 1999). Briefly, $10 \mathrm{~g}$ of macerated cherry purée or cherry beverage were resuspended in 50 $\mathrm{mL}$ of methanol solution ( $0.1 \%$ hydrochloric acid) for $24 \mathrm{~h}$ at $-20^{\circ} \mathrm{C}$. The absorbance of the resulting extracts was analyzed by measuring the absorbance of the solvent, previously filtered, in a UV-2401PC Shimadzu spectrophotometer (Scientific Instruments, Inc., Columbia, MD., USA) at $520 \mathrm{~nm}$. The total concentration of anthocyanins was calculated from a calibration curve of chloride-cynidin-3-glucoside, and the results were expressed in $\mathrm{mg} / 100 \mathrm{~g}$ sample.

\section{Detection and quantification of the indole serotonin} Serotonin determination was carried out according to the method previously described by González-Gómez et al. (2009) with slight modifications. $2 \mathrm{~g}$ of lyophilized fruit, corresponding to $10 \mathrm{~g}$ of cherry purée or beverage, were added to $10 \mathrm{~mL}$ of phosphate buffer $(\mathrm{pH}=8)$. The homogenized samples were centrifugated for $10 \mathrm{~min}$ at $4^{\circ} \mathrm{C}$ at $1,000 \mathrm{rpm}$ and filtered. The filtered samples were rinsed with $5 \mathrm{ml}$ of phosphate buffer $(0.05 \mathrm{M}, \mathrm{pH}=8)$ and the aqueous phase was isolated. Afterwards, $3 \mathrm{ml}$ of chloroform and $300 \mathrm{~mL}$ of $\mathrm{KOH}(0.1 \mathrm{M})$ were added and the mixture was shaken for $5 \mathrm{~min}$. Then, the mixture was dried under a nitrogen stream and reconstituted with $200 \mu \mathrm{L}$ of formic acid $(0.45 \%)$ solution. Processed samples were analyzed using a high-performance liquid chromatography system with an electrospray ionization mass spectrometry (HPLC-MS/ESI) - quadrupole detector (Agilent 1100). Separation was achieved on a Xterra C 18 HPLC column $(100 \mathrm{~mm} \times 2.1 \mathrm{~mm}, 3.5 \mu \mathrm{m}$; Waters Cromatografia, S.A., Barcelona, Spain), thermostatted at $30^{\circ} \mathrm{C}$. Formic acid $(0.45 \%)$ and acetonitrile were used as mobile phase with the following gradient: starting with $5 \%$ of acetonitrile an isocratic elution was applied for $5 \mathrm{~min}$; then, a gradient was installed to obtain $100 \%$ of acetonitrile at min 8 , and maintained until $16 \mathrm{~min}$. The injected volume was $50 \mu \mathrm{l}$.

After peak characterization, serotonin determination was performed by selected ion monitoring (SIM) of the generated ions (m/z 177 for serotonin). Quantitative calculations were conducted with the peak area of serotonin. ACOC software was used for the calibration and statistic calculations, and Agilent ChemStation software 
Garrido, et al.

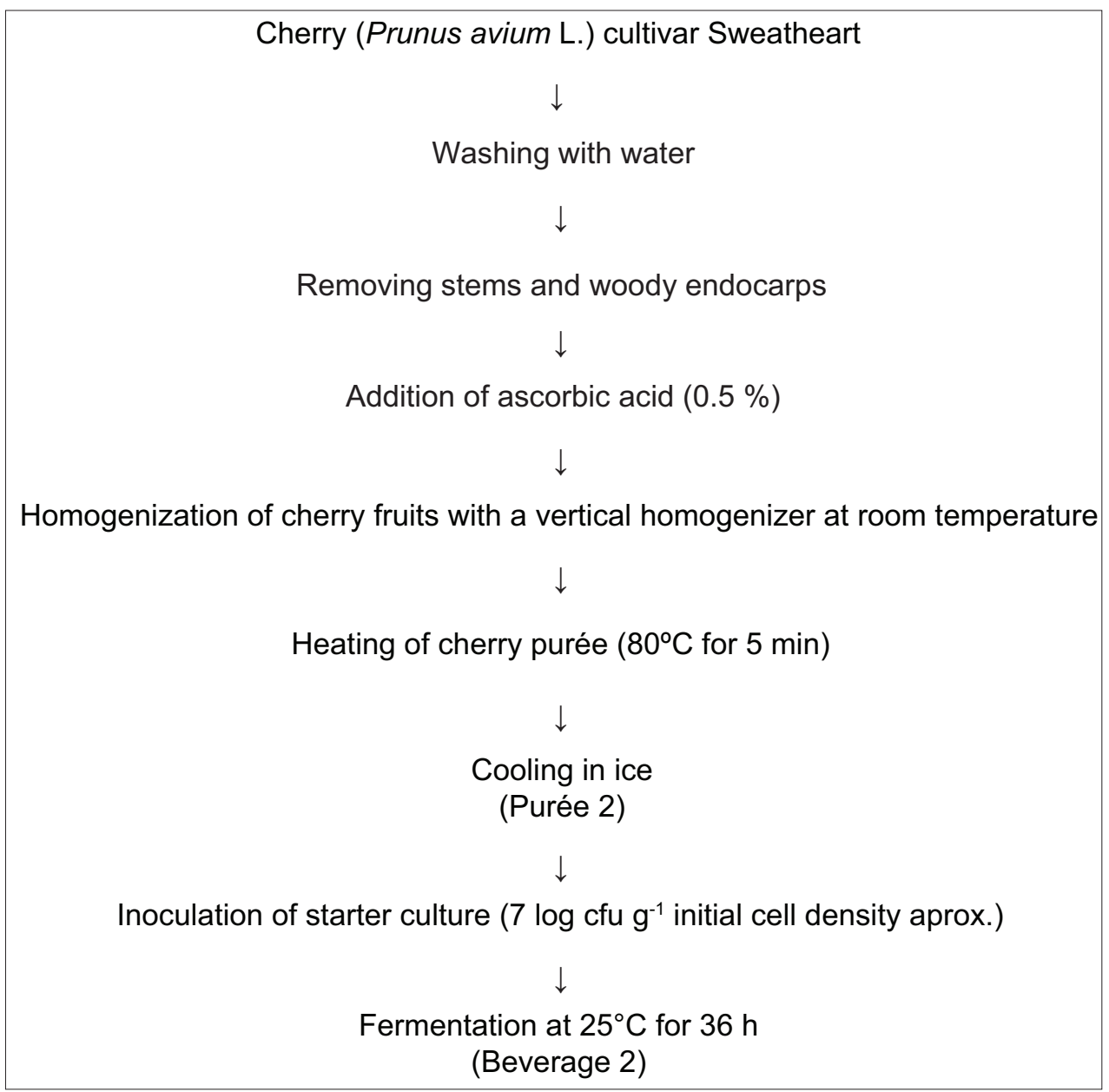

Scheme 2. Protocol for the elaboration of the fermented cherry-based beverage 2 .

for data acquisition and peak area integration (GonzálezGómez et al., 2009).

\section{Detection and quantification of amino acids}

The amino acid profile of both cherry purées and fermented-cherry beverages were analyzed according to Valdés et al. (2011). Samples were subjected to a previous process of deproteinization by addition of aqueous solution of sulfosalicylic acid 5\% (v/v) (PA Panreac) kept for $1 \mathrm{~h}$ at $4{ }^{\circ} \mathrm{C}$, and centrifuged (14000 rpm, $\left.5 \mathrm{~min}\right)$. The supernatant obtained was filtered through a $0.22-\mu \mathrm{m}$-poresize filter (Millex-GV; PVDF, Merck-Millipore, Germany). The separation and quantification of amino acids were performed by ion exchange chromatography (HPLC) using lithium citrate buffers as eluents, at different concentrations $(0.2,0.3,0.5,0.9$ and $1.65 \mathrm{M})$ followed by post-column detection performed by the ninhydrin reaction of the amino groups to form colored derivatives using a Biochrom 30 series amino acid analyzer (Biochrom Ltd., Cambridge Science Park, England). The amino acid-ninhydrin complex was detected spectrophotometrically at $440 \mathrm{~nm}$ for proline and hydroxyproline and $570 \mathrm{~nm}$ for the rest of the amino acids.
The calibration standard was prepared using the amino acid standard solutions 'Acidics and Neutrals' (Sigma A6407) and 'Basics' (Sigma A6282) in which were added the required additional amino acids. EZ Chrom Elite Software was used to data analysis.

\section{Trolox equivalent antioxidant capacity (TEAC)}

Antioxidant activity was evaluated according to a method previously published (Cano et al., 1998), but slightly modified. Briefly, $20 \mathrm{~mL}$ of cherry extract obtained from cherry fruit, purée, and beverage was placed in to a spectrophotometric cuvette, and $1 \mathrm{~mL}$ of the radical cation ABTS (2,20- azinobis(3-ethylbenzoithiazolone 6-sulphonate) was added. The measurements were carried out in a UV-2401PC Shimadzu spectrophotometer (Shimadzu Scientific Instruments Inc., Columbia, MD, Usa). The TEAC was expressed as $\mathrm{mg}$ of Trolox per $100 \mathrm{~g}$ of sample.

\section{Statistical analysis}

Data are presented as mean \pm standard deviation (SD) of the numbers of determinations. The results were analyzed using a one-way analysis of variance (ANOVA) 
followed by Tukey's multiple range test. The significance level was set at $\mathrm{p}<0.05$. All analyses were performed using Statistical Package SPSS 17.0 version for Windows (SPSS Inc., Chicago, IL, USA).

\section{RESULTS AND DISCUSSION}

Currently, a wide assortment of minimally processed fruits and vegetables has been developed to meet consumer's demands for 'easy' and convenient products, and to benefit from vegetable and fruit's healthy perception. For this reason, minimally processed products are one of the major growing sections in food retail establishments.

Lactic acid fermentation is an important biotechnology for maintaining and/or improving nutritional, sensory, safety and shelf-life properties of fruits and vegetables. Growth and viability of lactic acid bacteria, in particular L. plantarum and L. pediococci, has been frequently shown on plant materials where polyphenolic compounds are abundant (Di Cagno et al., 2011; Torres et al., 2020). In the present study, both L. plantarum and P. pentosaceus were tested for carrying out the lactic acid fermentation of cherry beverages. After incubation for 36 hours at $25^{\circ} \mathrm{C}$, L. plantarum grew from $6.35 \pm 0.46$ to of $9.83 \pm 0.13 \mathrm{log}$ CFU ml ${ }^{-1}$, whereas $P$. pentosaceus grew from $6.83 \pm 0.63$ to $8.27 \pm 0.52 \log \mathrm{CFU} \mathrm{m} l^{-1}$ of cell density. Based on these results, L. Plantarum was selected as the starter culture since it reached the stationary phase earlier and with higher concentration (data not shown) than P. Pentosaceus.

\section{Color evaluation}

Food color is governed by the biochemical, physical, chemical and microbial changes which occur during growth, maturation, postharvest handling and processing. Actually, it is worldwide assumed that visual appearance of foodstuffs influences consumer's sensory acceptance. Table 1 shows the instrumental color of cherry fruit, cherry purées as well as fermented-cherry beverages obtained following the two different protocols proposed for the elaboration of the fermented-cherry beverages (protocol 1 and protocol 2). Based on the CIELAB color system, the processing methods produced significant $(\mathrm{p}<0.05)$ variations in the vast majority of the instrumental color parameters evaluated. The protocol 2 for the elaboration of the fermented-cherry beverage was more effective in terms of lightness $\left(\mathrm{L}^{*}\right)$ since both purée and beverage 2 exhibited the highest values $(p<0.05)$. In particular, the $L^{*}$ value reached nearly a 2 -fold increase in beverage 2 with respect to the fresh fruit. Related to parameter $\mathrm{a}^{*}$, it was higher $(\mathrm{p}<0.05)$ in both purées $(1$ and 2 ), such a value being remarkably elevated in purée 2 . The chromatic parameter $b^{*}$ was noticeably $(p<0.05)$ lower in fresh fruit than in processed-cherry products, reaching the highest value in fermented-cherry beverage 2. Yellowness-browning may be, at least partly, due to both enzymatic and non-enzymatic oxidation of phenolic compounds, particularly anthocyanins. This fact is extremely relevant since enzymatic browning is a major factor generating sensorial and functional quality loss in foodstuffs. In order to reduce/prevent this phenomenon, ascorbic acid was added to the elaboration of both fermented-cherry beverages. In fact, ascorbic acid has been the main Generally Recognized As Safe (GRAS) antioxidant used for prevention of browning and other oxidative reactions on fruit-based food products. The quantitative attribute of colorfulness, i.e., chroma $\left(\mathrm{C}^{*}\right)$ was also evaluated. It is well known that the higher the chroma value, the higher the color intensity of samples perceived by humans. According to this, purée 2 and beverage 2 exhibited the highest $(\mathrm{p}<0.05)$ color intensity. Hue angle (h) has also been largely used in the evaluation of color parameter in vegetables and fruits. We found significant $(\mathrm{p}<0.05)$ mean $\mathrm{h}$ values ranging from $18.03^{\circ}$ (cherry fruit) to $51.39^{\circ}$ (fermented-cherry beverage 2), this range corresponding with the reddish tone in the CIELAB system.

Based on these results, the variations in the color could be influenced by the step of the processing in which the ascorbic acid was added, i.e., after (protocol 1) or before (protocol 2) the homogenization and pasteurization processes. Since less change was detected in fermentedcherry beverage 2 and higher values of lightness and redness were found both in purée and beverage 2 , we could assume, that the moment time of addition of ascorbic acid influenced the color attributes of the unprocessed and processed-cherry products.

Table 1: Total color difference changes of fresh cherry fruit and cherry-processed products through lactic acid fermentation

\begin{tabular}{lcccrr}
\hline & $L^{*}(\mathbf{D} 65)$ & $\mathbf{a}^{*}(\mathbf{D} 65)$ & $\mathbf{b}^{*}(\mathbf{D} 65)$ & $\mathbf{C}^{*}(\mathbf{D} 65)$ & $\mathbf{h}(\mathbf{D} 65)$ \\
\hline Fresh cherry & $25.16 \pm 0.34^{\mathrm{e}}$ & $22.99 \pm 0.95^{\mathrm{c}}$ & $7.49 \pm 0.56^{\mathrm{e}}$ & $24.18 \pm 1.07^{\mathrm{d}}$ & $18.03 \pm 0.56^{\mathrm{e}}$ \\
Purée 1 & $30.26 \pm 1.35^{\mathrm{d}}$ & $26.71 \pm 0.95^{\mathrm{b}}$ & $12.90 \pm 0.58^{\mathrm{d}}$ & $29.67 \pm 1.06^{\mathrm{c}}$ & $25.78 \pm 0.62^{\mathrm{c}}$ \\
Beverage 1 & $32.31 \pm 0.53^{\mathrm{c}}$ & $18.86 \pm 0.31^{\mathrm{d}}$ & $15.04 \pm 0.50^{\mathrm{c}}$ & $24.12 \pm 0.55^{\mathrm{d}}$ & $38.56 \pm 0.53^{\mathrm{b}}$ \\
Purée 2 & $35.14 \pm 0.93^{\mathrm{b}}$ & $41.95 \pm 1.17^{\mathrm{a}}$ & $17.86 \pm 1.41^{\mathrm{b}}$ & $45.60 \pm 1.61^{\mathrm{a}}$ & $23.03 \pm 1.08^{\mathrm{d}}$ \\
Beverage 2 & $48.34 \pm 0.91^{\mathrm{a}}$ & $21.27 \pm 0.46^{\mathrm{c}}$ & $26.65 \pm 1.22^{\mathrm{a}}$ & $34.09 \pm 1.24^{\mathrm{b}}$ & $51.39 \pm 0.67^{\mathrm{a}}$ \\
\hline
\end{tabular}

$L^{*}$ : lightness; a*: red \pm green; $b^{*}$ : yellow \pm blue; $C^{*}$ : chroma; $h$ : hue angle. Different letters in the same row indicate significant differences $(p<0.05)$. Data represent mean \pm SD of three samples run in triplicate. 


\section{Analysis of phenolic compounds}

Among fruits, cherry is considered a major source of phenolic compounds, which are responsible for its sensory properties such as bitterness and astringency, as well as of its color. Moreover, these bioactive compounds have long-term human health benefits due to their wide range of biological properties including antiallergic, antioxidant, anticarcinogenic, antimitagenic, antimicrobial and antiinflamatory activities (Blando and Oomah, 2019; Faienza et al., 2020).

\section{Total polyphenols content}

As shows in Figure 1, Sweetheart cherries possess elevated amount of phenolics, around $400 \mathrm{mg}$ gallic acid/100 $\mathrm{g}$ fresh fruit. This concentration is higher compared than that found in other sweet cherry varieties, such as Bing cherries, which possess 160-170 $\mathrm{mg}$ gallic acid/100 $\mathrm{g}$ fresh fruit (Chaoanalikit and Wrolstad, 2004). However, in both cherry purée 1 and purée 2 the phenol concentrations decreased significantly $(\mathrm{p}<0.05)$ with respect to cherry fresh fruit. These results are in accordance with other studies that have been reporting that phenolic degradation is one of the adverse effects of thermal pasteurization (Chen et al., 2013). In fact, this technique may cause physical and chemical reactions affecting the phenolic composition, including the release of phenolic compounds from their bonded forms, the degradation of polyphenols and the breakdown and transformation of phenolics (Chen et al., 2013). Nevertheless, the subsequent add of lactic acid bacteria remarkably increased $(p<0.05)$ the bioavailability of these compounds, the fermented-cherry beverage 1 (352.29 \pm 1.06$)$ and $2(371.67 \pm 13.91)$ showing similar to cherry fresh fruit value $(394.58 \pm 8.61)$. It has been demonstrated that lactic fermentation processing alters the chemical nature and efficacy of phenolic constituents in foodstuffs (Kachouri et al., 2015). On the one hand, L. plantarum is one of the lactobacilli that metabolizes phenolic acids through decarboxylation and/or reduction activities. Further metabolic pathways identified in lactobacilli are based on: esterases which degrades methyl gallate, tannins, or phenolic acid esters and glycosyl hydrolases, which convert flavonoid glycosides to the corresponding aglycones (Torres et al., 2020). On the other hand, it has been described that lactic acid bacteria are involved in the production of volatile phenols (Fras et al., 2014). Consequently, the elevation of total phenolic compounds in the cherry-fermented beverages could be due to the bioconversion and/or

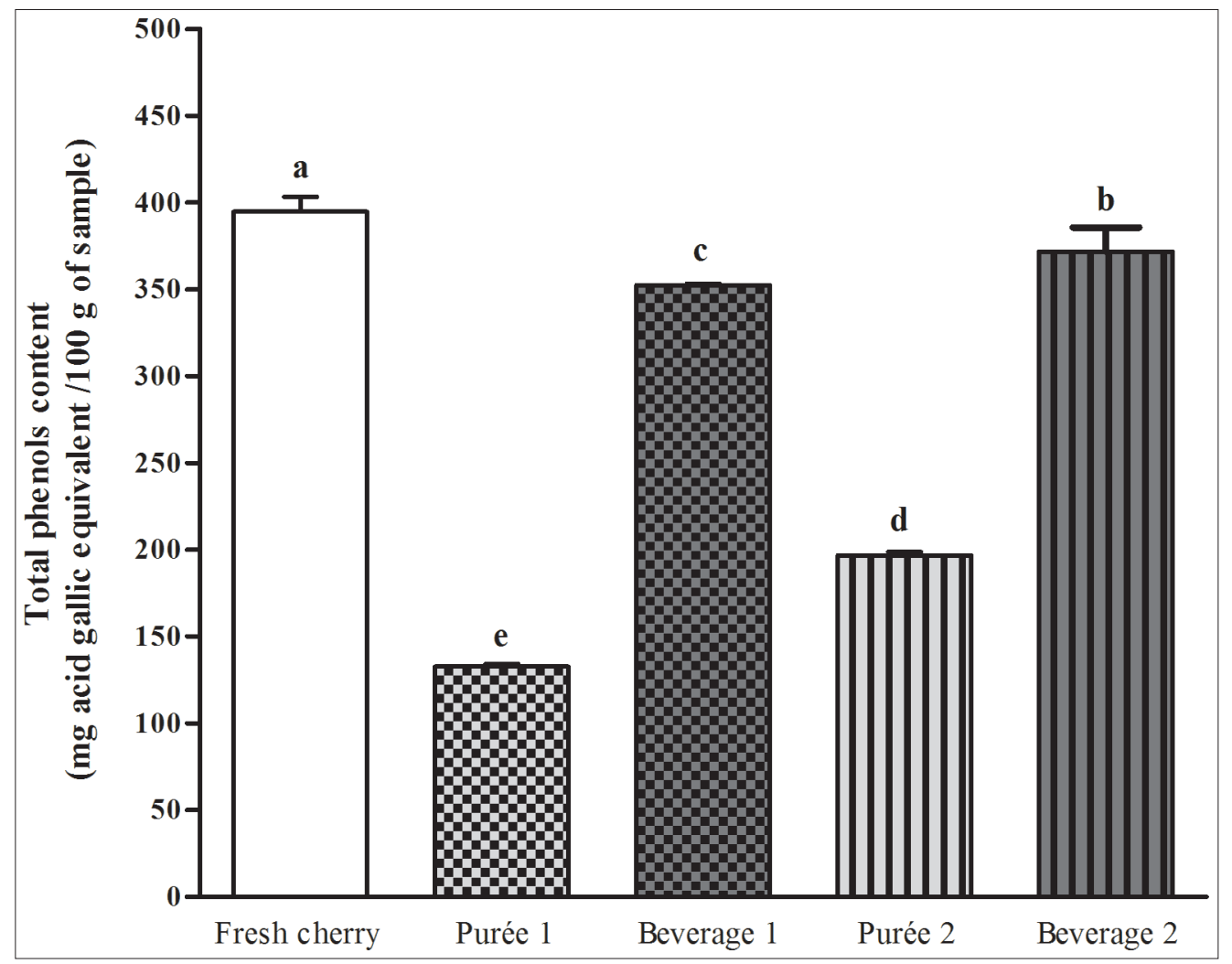

Fig 1. Total phenols content (mg acid gallic equivalent/100 g sample) found in fresh cherry, cherries, cherry purées and fermented-cherry beverages elaborated through two different lactic acid fermentation processes. Purée 1: cherry purée obtained following the protocol 1; Beverage 1: fermented-cherry beverage obtained following the protocol 1; Purée 2: cherry purée obtained following the protocol 2; Beverage 2: fermentedcherry beverage obtained following the protocol 2 . Different letters in the same row indicate significant differences $(p<0.05)$. Data are expressed as mean \pm SD of three samples run in triplicate. 
increase of phenolic compounds during the fermentation processes.

It is important to highlight that both purée 2 and beverage 2 presented higher $(p<0.05)$ phenols content that those obtained in both purée and cherry-beverage 1. It may suggest that the addition of ascorbic acid previous to the cherry homogenization process (protocol 2) partly prevented the reduction of total phenolic compounds observed in purée 1 and beverage 1 (protocol 1). Therefore, the addition of ascorbic before the homogenization may be a crucial factor to optimize the elaboration of the fermented-cherry beverage.

\section{Anthocyanins content}

Red color in berries is due to the presence of anthocyanins, one of the principal groups of pigments in these fruits. Cherries are known to have anthocyanins as the leading phenolics, being cyanidin-3-O-glucoside and cyanidin-3-Orutinoside the most abundant types (González-Gómez et al., 2010). These compounds are largely responsible for the strong antioxidant activities that present both unprocessed and processed cherry fruit. The stability of anthocyanins and therefore, its potential as an antioxidant is closely related to the processing (Kouniaki et al., 2004; Patras et al., 2010). In fact, anthocyanin pigments are highly sensitive and readily degrade during the numerous processing and storage of foodstuffs, which can have a deep impact on color quality and may also affect nutritional composition.

Figure 2 exhibits the total anthocyanin concentration quantified in fresh cherry fruit, cherry purées and fermented-cherry beverages obtained with the protocols 1 and 2. The highest anthocyanin content was detected in fresh cherry fruit, these value being significantly $(\mathrm{p}<0.05)$ elevated with respect to those obtained in purée $1(8.84 \pm 0.07)$ and purée $2(8.96 \pm 0.17)$. In addition, no differences were detected between both purées, which could mean that the time for the addition of ascorbic acid did not influence the anthocyanin content. However, magnitude and duration of heating during pasteurization processes may cause a negative influence on anthocyanin stability since the levels of this pigment were reduced in both purees. At this respect, it has been reported that berries anthocyanin content is sensitive to thermal treatments (Patras et al., 2010). Moreover, several studies have described a logarithmic course of anthocyanin destruction with an arithmetic increase in temperature (Patras et al.,

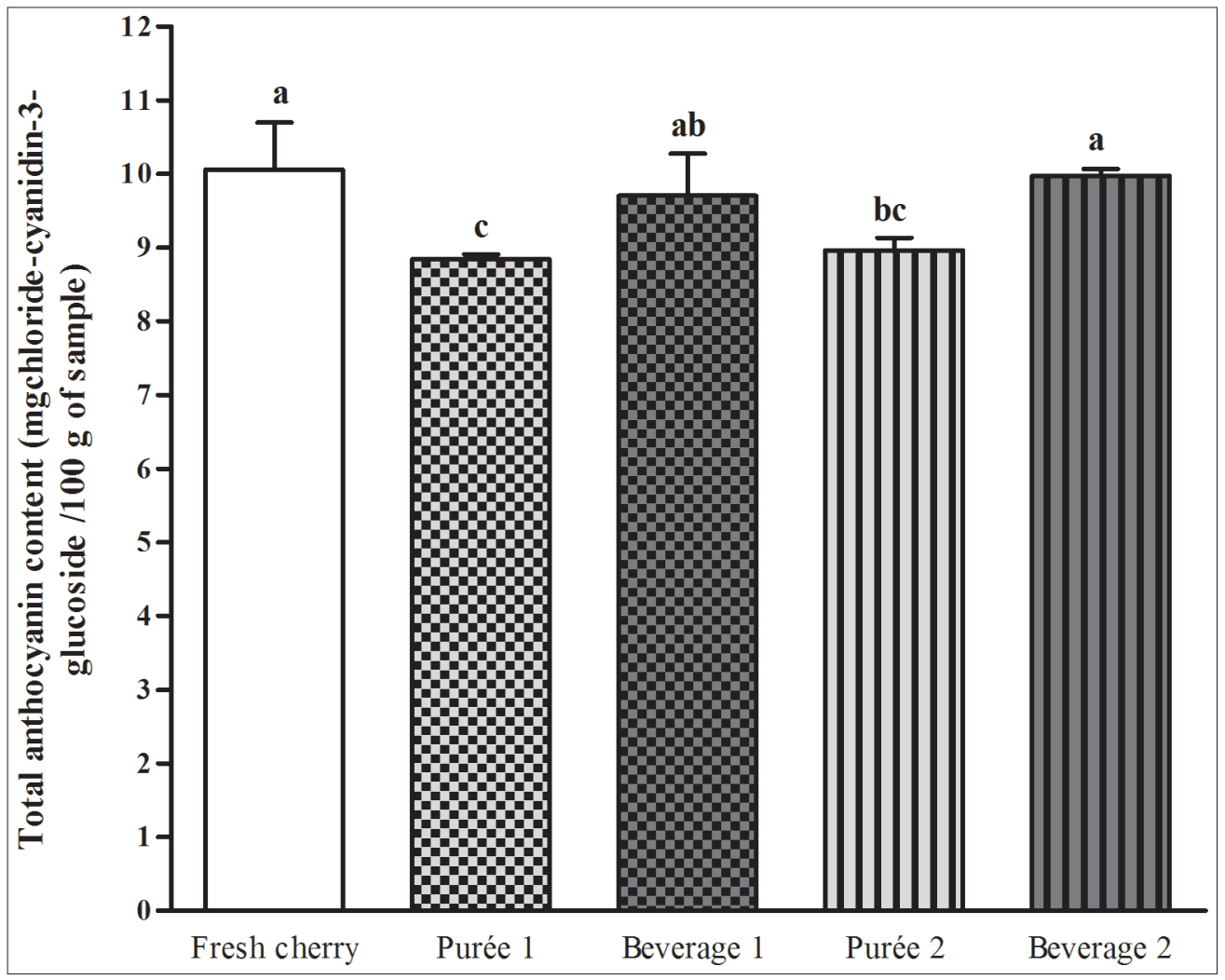

Fig 2. Total anthocyanin content (mg acid chloride-cyanidin-3-glucoside/100 g sample) found in fresh cherry, cherry purées and fermentedcherry beverages elaborated through two different lactic acid fermentation processes. Purée 1: cherry purée obtained following the protocol 1; Beverage 1: fermented-cherry beverage obtained following the protocol 1; Purée 2: cherry purée obtained following the protocol 2; Beverage 2: fermented-cherry beverage obtained following the protocol 2. Different letters in the same row indicate significant differences $(p<0.05)$. Data are expressed as mean \pm SD of three samples run in triplicate. 
2010). Nevertheless, it is worthy to highlight that the levels of this natural pigment detected in both fermented-cherry beverage $1(9.70 \pm 0.56)$ and beverage $2(9.97 \pm 0.09)$ were raised. It means that the lactic acid fermentation improved $(p<0.05)$ the anthocyanin content with respect to those obtained in purées. At this respect, it has been reported that Lactobacillus had $\beta$-glucosidase activity and participates in the hydrolysis of plant $\beta$-glycosides (Ávila et al., 2009), which results in increased levels of their aglycone form (anthocyanidin). Therefore, the elevation on these pigments observed herein may be linked with the degradation and/ or bioconversion of complex molecules to simple ones due to the $\beta$-glucosidase activity. It is important to highlight that there were not statistical differences on this functional parameter between the fermented-cherry beverages and fresh fruit. Consequently, both fermentation protocols managed to maintain the anthocyanin content at the same concentration than that found in the raw matrix.

\section{Detection and quantification of the indole serotonin}

Serotonin is a well-known physiologically active amine in the animal kingdom. It possesses hormonal, antioxidant, immunomodulatory and neuroactive biological properties (Pilowsky, 2018). In the last decade, it has also been found in a wide variety of plant species (Akula et al., 2011). Fruits, vegetables and seeds are the major matrices in which serotonin occur in abundance. Among fruits, sweet cherries, in particular, Jerte Valley cherries (Extremadura, Spain), contain high levels of this neurotransmitter (González-Gómez et al., 2009). Moreover, it has been demonstrated that a number of their health benefits are, at least in part, due to their serotonin content (Garrido et al., 2012; Rocha-Pimienta et al., 2019).

The results revealed that the processing of cherry fruit did not influence the serotonin content present in the different processed cherry products studied (Figure 3). Although no statistical differences were detected, the serotonin levels found in purée 2 and fermented-cherry beverage 2 were slightly elevated with respect to those obtained in purée and cherry-beverage 1, respectively. According to these results, the lactic acid fermentation processing was a suitable process for preserving the serotonin content. At this respect, it has been recently reported that the intake of the cherry-based fermented beverage elevates the circulatory serotonin levels in an in vivo model (RochaPimienta et al., 2019). The conservation of serotonin is particularly relevant since it is the direct precursor of the

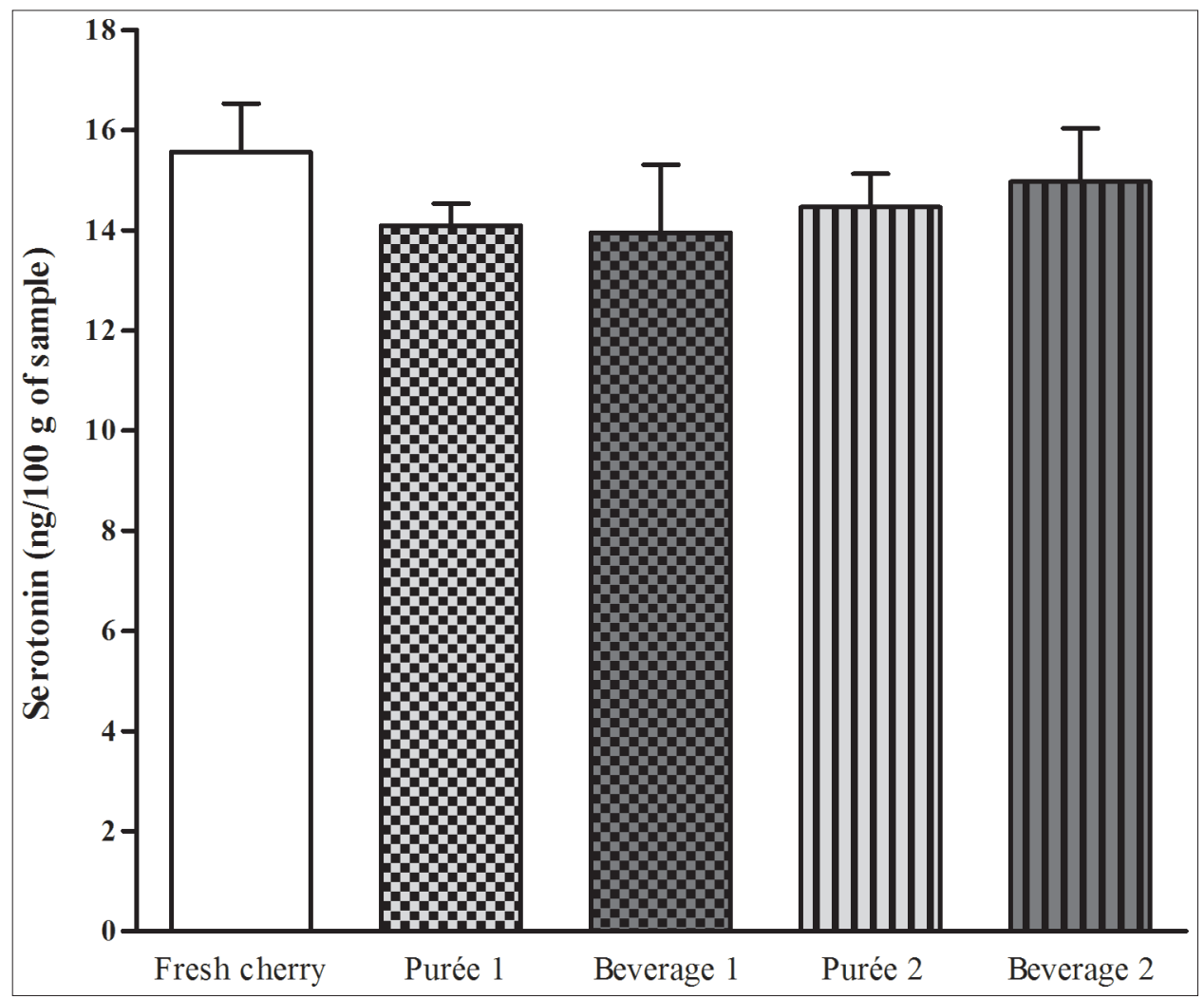

Fig 3. Serotonin levels (ng/100 g sample) found in fresh cherry, cherry purées and fermented-cherry beverages elaborated through two different lactic acid fermentation processes. Purée 1: cherry purée obtained following the protocol 1; Beverage 1: fermented-cherry beverage obtained following the protocol 1; Purée 2: cherry purée obtained following the protocol 2; Beverage 2: fermented-cherry beverage obtained following the protocol 2. Different letters in the same row indicate significant differences $(p<0.05)$. Data are expressed as mean $\pm S D$ of three samples run in triplicate. 
indole melatonin, a neuroactive substance that provides a wide range of physiological benefits.

\section{Characterization of the amino acid profile}

Amino acids are biologically organic compounds that play essential roles both as intermediates in metabolism and as building blocks of proteins, acting as precursors for many coenzymes, hormones, nucleic acids, and other important molecules. They are present at relatively low levels in foodstuffs compared to other bioactive molecules; however, they represent an integral part of the foodstuffs nutritional value. It has long been known that the amino acid composition of fresh food is changed by both technological processing and storage and, therefore, it is crucial to evaluate the amino acid profile of the final product as a key element of its nutritional value (Hurrell and Finot, 1983).

Table 2 shows the amino acid composition of the cherry purées and fermented-cherry beverages studied. Forty amino acids composed the amino acid profile of the processedcherry products. Among them, essential (threonine, valine, methionine, isoleucine, leucine, phenylalanine, lysine,

Table 2: Amino acid profile identified in cherry purées and fermented-cherry beverage obtained through two different lactic fermentation processes (protocol 1 and protocol 2)

\begin{tabular}{|c|c|c|c|c|}
\hline Amino acid & Purée 1 (mg/L) & Purée 2 (mg/L) & Beverage 1 (mg/L) & Beverage $2(\mathrm{mg} / \mathrm{L})$ \\
\hline Phenilserine & $14.84 \pm 0.51^{c}$ & $17.46 \pm 0.13^{b}$ & $20.18 \pm 0.13^{a}$ & $20.72 \pm 0.90^{a}$ \\
\hline Taurine & $44.81 \pm 0.27^{a}$ & $37.56 \pm 0.44^{b}$ & $43.31 \pm 0.62^{a}$ & $38.43 \pm 2.03^{b}$ \\
\hline Phenylethylamine & $2.23 \pm 0.09$ & $2.60 \pm 0.60$ & $5.08 \pm 4.28$ & $3.26 \pm 0.34$ \\
\hline Urea & $7.50 \pm 2,97$ & $6.18 \pm 2.21$ & $10.68 \pm 7.30$ & $9.81 \pm 4.37$ \\
\hline Aspartic acid & $39.83 \pm 1.41^{b}$ & $43.69 \pm 2.16^{b}$ & $52.33 \pm 1.03^{a}$ & $51.80 \pm 1.41^{\mathrm{a}}$ \\
\hline Threonine & $22.01 \pm 0.34^{\mathrm{a}}$ & $21.30 \pm 0.00^{a}$ & $17.07 \pm 0.25^{b}$ & $15.05 \pm 0.59^{c}$ \\
\hline Serine & $30.66 \pm 0.59^{a}$ & $29.82 \pm 0.00^{a}$ & $27.30 \pm 1.04^{b}$ & $25.88 \pm 0.97^{b}$ \\
\hline Asparagine & $1643.40 \pm 0.00^{b}$ & $1157.64 \pm 0.00^{d}$ & $1734.48 \pm 0.00^{a}$ & $1257.96 \pm 0.00^{c}$ \\
\hline Glutamic acid & $204.33 \pm 0.00^{\circ}$ & $157.29 \pm 0.00^{d}$ & $382.20 \pm 0.00^{a}$ & $298.41 \pm 0.00^{b}$ \\
\hline Sarcosine & $15.88 \pm 1.95^{\mathrm{a}}$ & $10.90 \pm 1.07^{b}$ & $17.04 \pm 0.57^{a}$ & $10.85 \pm 1.89^{b}$ \\
\hline Glycine & $13.61 \pm 0.90^{a}$ & $4.500 \pm 0.74^{b}$ & $14.17 \pm 0.21^{a}$ & $4.65 \pm 0.95^{b}$ \\
\hline Citrulline & $12.60 \pm 0.25^{c}$ & $10.93 \pm 0.37^{c}$ & $23.10 \pm 1.24^{\mathrm{a}}$ & $16.36 \pm 0.37^{b}$ \\
\hline Alanine & $15.75 \pm 0.00^{a}$ & $16.77 \pm 0.06^{a}$ & $13.17 \pm 0.13^{b}$ & $10.54 \pm 0.19^{c}$ \\
\hline$\alpha$-aminobutyric acid & $2.16 \pm 0.00^{b c}$ & $2.00 \pm 0.07^{c}$ & $3.29 \pm 0.00^{\mathrm{a}}$ & $2.67 \pm 0.00^{\mathrm{ab}}$ \\
\hline Valine & $28.8 \pm 0.08^{a}$ & $22.05 \pm 0.25^{c}$ & $25.09 \pm 0.25^{b}$ & $15.85 \pm 0.41^{d}$ \\
\hline Cystine & $0.60 \pm 0.00$ & $0.18 \pm 0.26$ & $0.60 \pm 0.00$ & $0.36 \pm 0.00$ \\
\hline Methionine & $1.49 \pm 0.00^{a}$ & $1.11 \pm 0.11^{\mathrm{a}}$ & $0.00^{b}$ & $0.00^{b}$ \\
\hline Cystathionine & 0.00 & 0.00 & 0.00 & 0.00 \\
\hline Isoleucine & $6.23 \pm 0.09^{a}$ & $6.87 \pm 0.09^{a}$ & $2.35 \pm 0.0^{b}$ & $1.37 \pm 0.09^{b}$ \\
\hline Leucine & $6.94 \pm 0.00^{a}$ & $6.87 \pm 0.09^{a}$ & $2.62 \pm 0.37^{b}$ & $0.85 \pm 0.09^{b}$ \\
\hline Tyrosine & $11.22 \pm 0.26^{b}$ & $14.02 \pm 0.13^{a}$ & $14.02 \pm 2.43^{a b}$ & $14.75 \pm 0.64^{a}$ \\
\hline$\beta$-alanine & $9.16 \pm 0.25^{a}$ & $3.56 \pm 0.00^{b}$ & $9.79 \pm 1.38^{a}$ & $3.60 \pm 0.06^{b}$ \\
\hline Phenylalanine & $3.54 \pm 0.12^{a}$ & $3.46 \pm 0.23^{a b}$ & $2.14 \pm 0.23^{b}$ & $0.74 \pm 0.12$ \\
\hline$\beta$ - aminobutyric acid & $0.15 \pm 0.22^{a}$ & $0.00^{b}$ & $0.15 \pm 0.22^{a}$ & $0.00^{b}$ \\
\hline Homocysteine & $27.33 \pm 0.10^{a}$ & $16.20 \pm 0.19^{b}$ & $25.65 \pm 0.19^{a}$ & $15.99 \pm 0.48^{b}$ \\
\hline$\gamma$-aminobutyric acid & $5.56 \pm 0.00$ & $5.51 \pm 0.66$ & $5.45 \pm 0.00$ & $5.87 \pm 0.15$ \\
\hline Ethanolamine & 0.00 & 0.00 & 0.00 & 0.00 \\
\hline Methylmalonic acid & 0.00 & 0.00 & 0.00 & 0.00 \\
\hline Hydroxilysine & $1.62 \pm 0.00^{a}$ & $0.00^{b}$ & $0.00^{b}$ & $0.00^{b}$ \\
\hline Ornithine & $1.45 \pm 0.19$ & $1.45 \pm 0.00$ & $1.84 \pm 0.37$ & $1.51 \pm 0.09$ \\
\hline Lysine & $1.45 \pm 0.19^{c}$ & $8.61 \pm 0.00^{a}$ & $7.66 \pm 0.10^{a}$ & $4.74 \pm 0.10^{b}$ \\
\hline 1-methylhistidine & $8.24 \pm 0.10^{a}$ & $2.36 \pm 0.00^{b}$ & $2.45 \pm 0.12^{b}$ & $2.19 \pm 0.24^{b}$ \\
\hline Histidine & $2.70 \pm 0.00^{c}$ & $9.99 \pm 0.11^{b}$ & $15.42 \pm 0.33^{a}$ & $10.15 \pm 0.33^{b}$ \\
\hline Tryptophan & $14.95 \pm 0.11^{\mathrm{a}}$ & $8.87 \pm 0.14^{c}$ & $10.09 \pm 0.43^{b}$ & $8.87 \pm 0.43^{b c}$ \\
\hline 3-methylhistidine & $2.03 \pm 0.00$ & $1.94 \pm 0.12$ & $2.02 \pm 0.00$ & $1.94 \pm 0.12$ \\
\hline Anserine & 0.00 & 0.00 & 0.00 & 0.00 \\
\hline Carnosine & 0.00 & 0.00 & 0.00 & 0.00 \\
\hline Arginine & $5.74 \pm 0.00^{b}$ & $5.48 \pm 0.12^{b}$ & $6.69 \pm 0.12^{a}$ & $5.39 \pm 0.25^{b}$ \\
\hline Hydroxyproline & $0.917 \pm 1.30^{\mathrm{ab}}$ & $0.00^{b}$ & $1.37 \pm 1.95^{a}$ & $0.00^{b}$ \\
\hline Proline & $349.31 \pm 0.24^{\mathrm{a}}$ & $114.59 \pm 0.24^{b}$ & $340.17 \pm 0.81^{a}$ & $118.96 \pm 0.57^{b}$ \\
\hline TAAC & 2559.03 & 1751.76 & 2838.97 & 1979.52 \\
\hline
\end{tabular}

TAAC: total amino acid content. Different letters in the same row indicate significant difference $(p<0.05)$. All the data are mean \pm SD of three samples run in triplicate. 
histidine, tryptophan, arginine) and non-essential (serine, asparagine, glycine, alanine, cystine, tyrosine, proline) amino acids were detected and quantified. In general terms, values obtained in both varieties of amino acids followed the same trend, since levels in purées were higher than those found in fermented-cherry beverages. These reductions may be influenced by the lactic acid fermentation processes. Thus, this processing could promote either the conversion of primary molecules to other simple compounds or the inclusion of these molecules within complex structures that were not possible to detect by the method utilized.

It is worthy to focus on the amino acid tryptophan since it is involved in an extensive spectrum of physiological functions acting as a direct molecule or through its conversion in serotonin and, subsequently, in melatonin. Based on our results, among the four cherry-processed products characterized, the highest $(p<0.05)$ content of the essential amino acid tryptophan was detected in the cherry purée 1 (14.95 \pm 0.11$)$, whereas the lowest levels were found both in purée $2(8.87 \pm 0.14)$ and fermentedcherry beverage $2(8.87 \pm 0.43)$. Additionally, there were no statistical differences between fermented-cherry beverages $1(10.09 \pm 0.43)$ and cherry beverage $2(8.87 \pm 0.43)$.

Related to the total amino acid content (TAAC), the protocol 1 was more effective in terms of preservation and/or extraction of the amino acids than the protocol 2 (Table 2).

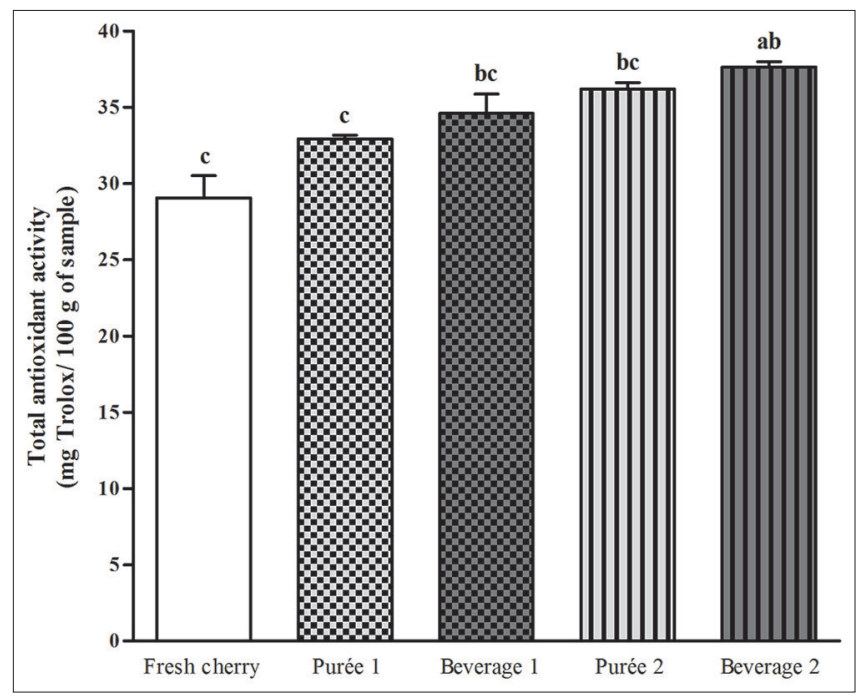

Fig 4. Total antioxidant activity ( $\mathrm{mg}$ Trolox/100 g sample) found in fresh cherry, cherry purées and fermented-cherry beverages elaborated through two different lactic acid fermentation processes. Purée 1: cherry purée obtained following the protocol 1; Beverage 1: fermentedcherry beverage obtained following the protocol 1; Purée 2: cherry purée obtained following the protocol 2; Beverage 2: fermented-cherry beverage obtained following the protocol 2. Different letters in the same row indicate significant differences $(p<0.05)$. Data are expressed as mean \pm SD of three samples run in triplicate.

\section{Trolox equivalent antioxidant capacity (TEAC)}

A large variety of bioanalytical methods for evaluation of antioxidant capacity of fruits and fruit-derived products, as well as fresh and processed vegetables has been proposed. These bioanalytical assays differ from each other in terms of oxidant and target species, reaction mechanisms, reaction conditions and expression form of results. Also, TEAC is dependent on a multitude of factors such as technological, agronomic or varietals factors (Coyago-Cruz et al., 2017; Sass-Kiss et al., 2010).

For many years, fermentation has been used as an important biotechnology for maintaining and improving foodstuffs properties. It has been reported that the use of starter microorganisms guaranteed the agreeable nutritional and sensory properties of fermented fruits and vegetables (Di Cagno et al., 2009; Yang et al., 2018).

Figure 4 shows that the TEAC detected in both fermentedcherry beverages is higher than that obtained in their corresponding purées, although these differences were not significant. The greatest TEAC was found in the fermented-cherry beverage 2 , this augmentation being significant $(\mathrm{p}<0.05)$ with respect to purée $1(32.92 \pm 0.25)$ and fresh fruit $(29.06 \pm 1.46)$, in which the lowest concentration of antioxidants was detected. Therefore, the TEAC of fresh cherry fruit was improved by the lactic fermentation process. Similar results were obtained by Di Cagno and colleagues, since they found the highest level of antioxidants in a fermented-cherry product compared to a cherry-purée (cherry puree added of $(10 \%, \mathrm{v} / \mathrm{v}$ ) stem infusion) before processing (Di Cagno et al., 2011). Likewise, other authors reported that leek fermented with lactic acid bacteria showed a higher antioxidant capacity than the fresh vegetable and was preferred by consumers (Wouters et al., 2013). Nevertheless, our results could be explained by a greater availability of antioxidant compounds or a rupture of complex molecules into simpler compounds. In this regard, several authors have reported an increase in the concentration of free phenolic compounds and antioxidant activity improvement in processed fruit and plant extracts by biotransformation (Macedo et al., 2011; Madeira et al., 2014). In this sense, it has been recently observed that the consumption of a cherry-based fermented beverage increases the total antioxidant capacity in vivo (Rocha-Pimienta et al., 2019).

\section{CONCLUSION}

The lactic fermentation of sweet cherries by L. plantarum as a starter culture would represent a novel technology option to completely exploit the potential of sweet cherries, in particular, Jerte Valley cherries, a fruit naturally rich in 
phytochemicals with in vivo healthy benefits. Moreover, the nutritional and functional properties of the cherryfermented beverages reveal their potential as prebiotic and probiotic supplements.

\section{ACKNOWLEDGEMENTS}

This work has been financed by European Regional Development Funds (ERDF) (GR15141). M. Garrido holds a research fellowship from Junta de Extremadura (ref. TA18029).

\section{Authors' contributions}

MG: data management and analysis, drafting of the manuscript. MEB: data acquisition, management and analysis. DM: data acquisition and management. JDA: study concept, study design, data analysis and review of the manuscript for important intellectual content.

\section{REFERENCES}

Akula, R., P. Giridhar and G. A. Ravishankar. 2011. Phytoserotonin: A review. Plant Signal. Behav. 6: 800-809.

Ávila, M., M. Hidalgo, C. Sánchez-Moreno, C. Pelaez, T. Requena and S. de Pascual-Teresa. 2009. Bioconversion of anthocyanin glycosides by Bifidobacteria and Lactobacillus. Food Res. Int. 42: $1453-1461$.

Bernalte, M. J., M. T. Hernández, M. C. Vidal-Aragón and E. Sabio. 1999. Physical, chemical, flavor and sensory characteristics of two sweet cherry varieties grown in "Valle del Jerte". J. Food Qual. 22: 403-416.

Blando, F. and B. D. Oomah. 2019. Sweet and sour cherries: Origin, distribution, nutritional composition and health benefits. Trends Food Sci. Technol. 86: 517-529.

Cano, A., J. Hernández-Ruíz, F. García-Cánovas, M. Acosta and M. B. Arnao. 1998. An end-point method for estimation of the total antioxidant activity in plant material. Phytochem. Anal. 9: 196-202.

Chaovanalikit, A. and R. E. Wrolstad. 2004. Total anthocyanins and total phenolics of fresh and processed cherries and their antioxidant properties. J. Food Sci. 69: FCT67-FCT72.

Chen, Y., L. J. Yu and H. P. V. Rupasinghe. 2013. Effect of thermal and non-thermal pasteurisation on the microbial inactivation and phenolic degradation in fruit juice: A mini-review. J. Sci. Food Agric. 93: 981-986.

Coyago-Cruz, E., M. Corell, A. Moriana, D. Hernanz, C. M. Stinco and A. J. Meléndez-Martínez. 2017. Effect of the fruit position on the cluster on fruit quality, carotenoids, phenolics and sugars in cherry tomatoes (Solanum lycopersicum L.). Food Res. Int. 100: 804-813.

Cubero, J., F. Toribio, M. Garrido, M. T. Hernández, J. Maynar, C. Barriga and A. B. Rodríguez. 2010. Assays of the amino acid tryptophan in cherries by HPLC-Fluorescence. Food Anal. Methods. 3: 36-39.

Delgado, J., M. P. Terrón, M. Garrido, C. Barriga, S. D. Paredes, J. Espino and A. B. Rodríguez. 2012. Systemic inflammatory load in young and old ringdoves is modulated by consumption of a Jerte Valley cherry-based product. J. Med. Food. 15: 707-712.
Di Cagno, R., R. F. Surico, G. Minervini, C. G. Rizzello, R. Lovino, M. Servili, A. Taticchi, S. Urbani and M. Gobbetti. 2011. Exploitation of sweet cherry (Prunus avium L.) puree added of stem infusion through fermentation by selected autochthonous lactic acid bacteria. Food Microbiol. 28: 900-909.

Di Cagno, R., R. F. Surico, A. Paradiso, M. De Angelis, J. C. Salmon, S. Buchin, L. De Gara and M. Gobbetti. 2009. Effect of autochthonous lactic acid bacteria starters on health-promoting and sensory properties of tomato juices. Int. J. Food Microbiol. 128: 473-483.

Espino, J., I. Bejarano, S. D. Paredes, C. Barriga, A. B. Rodríguez and J. A. Pariente. 2011. Protective effect of melatonin against human leukocyte apoptosis induced by intracellular calcium overload: Relation with its antioxidant actions. J. Pineal Res. 51: 195-206.

Faienza, M. F., F. Corbo, A. Carocci, A. Catalano, M. L. Clodoveo, M. Grano, D. Q. H. Wang, G. D'Amato, M. Muraglia, C. Franchini, G. Brunetti and P. Portincasa. 2020. Novel insights in health-promoting properties of sweet cherries. J. Funct. Foods. 69: 103945.

Fras, P., F. M. Campos, T. Hogg and J. A. Couto. 2014. Production of volatile phenols by Lactobacillus plantarum in wine conditions. Biotechnol. Lett. 36: 281-285.

Garrido, M., J. Espino, D. González-Gómez, M. Lozano, C. Barriga, S. D. Paredes and A. B. Rodríguez. 2012. The consumption of a Jerte Valley cherry product in humans enhances mood, and increases 5-hydroxyindoleacetic acid but reduces cortisol levels in urine. Exp. Gerontol. 47: 573-580.

González-Gómez, D., M. Lozano, M. F. Fernández-León, M. C. Ayuso, M. J. Bernalte and A. B. Rodríguez. 2009. Detection and quantification of melatonin and serotonin in eight Sweet Cherry cultivars (Prunus avium L.). Eur. Food Res. Technol. 229: 223-229.

González-Gómez, D., M. Lozano, M.F. Fernández-León, M. J. Bernalte, M. C. Ayuso, and A. B. Rodríguez. 2010. Sweet cherry phytochemicals: Identification and characterization by HPLC-DAD/ESI-MS in six sweet-cherry cultivars grown in Valle del Jerte (Spain). J. Food Compos. Anal. 23: 533-539.

Hugo, P. C., J. Gil-Chávez, R. R. Sotelo-Mundo, J. Namiesnik, S. Gorinstein and G. A. González-Aguilar. 2012. Antioxidant interactions between major phenolic compounds found in "Ataulfo" mango pulp: Chlorogenic, gallic, protocatechuic and vanillic acids. Molecules. 17: 12657-12664.

Hurrell, R. F. and P. A. Finot. 1983. Food processing and storage as a determinant of protein and amino acid availability. In: Experientia Supplementum. Vol. 44. Springer, Berlin, Germany, pp. 135-156.

Kachouri, F., H. Ksontini, M. Kraiem, K. Setti, M. Mechmeche and M. Hamdi. 2015. Involvement of antioxidant activity of Lactobacillus plantarum on functional properties of olive phenolic compounds. J. Food Sci. Technol. 52: 7924-7933.

Kouniaki, S., P. Kajda and I. Zabetakis. 2004. The effect of high hydrostatic pressure on anthocyanins and ascorbic acid in blackcurrants(Ribes nigrum). Flavour Frag. J. 19: 281-286.

Liao, X. Y., L. Q. Guo, Z. W. Ye, L. Y. Qiu, F. W. Gu and J. F. Lin. 2016. Use of autochthonous lactic acid bacteria starters to ferment mango juice for promoting its probiotic roles. Prep. Biochem. Biotech. 46: 399-405.

Lima, V. L. A., E. A. Mélo, M. I. S. Maciel, F. G. Prazeres, R. S. Musser and D. E. S. Lima. 2005. Total phenolic and carotenoid contents in acerola genotypes harvested at three ripening stages. Food Chem. 90: 565-568.

Linnewiel-Hermoni, K., M. Khanin, M. Danilenko, G. Zango, Y. Amosi, J. Levy, J. and Y. Sharoni. 2015. The anti-cancer effects of carotenoids and other phytonutrients resides in their combined 
activity. Arch. Biochem. Biophys. 572: 28-35.

Macedo, J. A., V. Battestin, M. L. Ribeiro and G. A. Macedo. 2011. Increasing the antioxidant power of tea extracts by biotransformation of polyphenols. Food Chem. 126: 491-497.

Madeira, J. V., V. M. Nakajima, J. A. Macedo, and G. A. Macedo. 2014. Rich bioactive phenolic extract production by microbial biotransformation of Brazilian Citrus residues. Chem. Eng. Res. Des. 92: 1802-1810.

Mulabagal, V., G. A. Lang, D. L. Dewitt, S. S. Dalavoy and M. G. Nair. 2009. Anthocyanin content, lipid peroxidation and cyclooxygenase enzyme inhibitory activities of sweet and sour cherries. J. Agr. Food Chem. 57: 1239-1246.

Nayak, B. N. and H. S. Buttar. 2016. Evaluation of the antioxidant properties of tryptophan and its metabolites in in vitro assay. J. Complement. Integr. Med. 13: 129-136.

Patras, A., N. P. Brunton, C. O'Donnell and B. K. Tiwari. 2010. Effect of thermal processing on anthocyanin stability in foods; mechanisms and kinetics of degradation. Trends Food Sci. Tech. 21: 3-11.

Pilowsky, P. M. 2018. Serotonin: The Mediator that Spans Evolution. Elsevier, United States.

Rocha-Pimienta, J., M. Garrido, D. Martin-Vertedor, A. B. Rodriguez and J. Delgado-Adamez. 2019. The effects of the intake of functional cherry beverage on non-specific immune parameters in rats. Eur. J. Hortic. Sci.
Sass-Kiss, A., M. Tóth-Markus, H. G. Daood, D. Bánáti, J. Nyéki and Z. Szabó. 2010. Effect of variety and cultivation technology on phenols and antioxidant activity of sweet and sour cherry. Int. J. Hortic. Sci. 16: 59-61.

Singleton, V. L. and J. A. Rossi. 1965. Colorimetry of total phenolics with phosphomolybdic-phosphotungstic acid reagments. Am. J. Enol. Viticult. 16: 144-158.

Torres, S., H. Verón, L. Contreras and M. I. Isla. 2020. An overview of plant-autochthonous microorganisms and fermented vegetable foods. Food Sci. Hum. Well. 9: 112-123.

Tsai, Y. T., P. C. Cheng and T. M. Pan. 2012. The immunomodulatory effects of lactic acid bacteria for improving immune functions and benefits. App. Microbiol. Biot. 96: 853-862.

Valdés, E., M. Vilanova, E. Sabio and M. J. Benalte. 2011. Clarifying agents effect on the nitrogen composition in must and wine during fermentation. Food Chem. 125: 430-437.

Wouters, D., N. Bernaert, N. Anno, B. Van Droogenbroeck, M. De Loose, E. Van Bockstaele and L. De Vuyst. 2013. Application' and validation of autochthonous lactic acid bacteria starter cultures for controlled leek fermentations and their influence on the antioxidant properties of leek. Int. J. Food Microbiol. 165: 121-133.

Yang, X., J. Zhou, L. Fan, Z. Qin, Q. Chen and L. Zhao. 2018. Antioxidant properties of a vegetable-fruit beverage fermented with two Lactobacillus plantarum strains. Food Technol Biotech. 27: 1719-1726. 